\title{
A criança e o tempo liberado da escola ${ }^{1}$
}

\author{
The child and the school-free time
}

Michelle Araújo Rocha ${ }^{[a]}$, Luciana Karine de Souza ${ }^{[b]}$

\footnotetext{
[a] Universidade Federal de Minas Gerais (UFMG), Belo Horizonte, MG - Brasil, e-mail: miche_ mar04@yahoo.com.br

${ }^{[b]}$ Universidade Federal de Minas Gerais, Belo Horizonte, MG -

Brasil, e-mail: lukarides@gmail. com
}

Recebido: 22/10/2012 Received: $10 / 22 / 2012$

Aprovado: $13 / 03 / 2013$ Approved: 03/13/2013

\section{Resumo}

Este estudo aborda as atividades realizadas pelas crianças quando liberadas do período escolar. Trata-se de uma pesquisa que se insere no campo de estudos interdisciplinares do lazer e que busca conhecer melhor como crianças ocupam o tempo fora da escola. Crianças de nove a dez anos de idade $(n=41)$, estudantes em duas escolas de Belo Horizonte, responderam a uma entrevista semiestruturada. As respostas foram examinadas qualitativamente sob análise de conteúdo. Diferenças importantes marcaram as atividades no tempo livre das crianças de escola pública e de escola privada. É necessário proporcionar vivências de lazer livre e não estruturado, especialmente em contextos que proporcionem aprendizagem e desenvolvimento social às crianças.

Palavras-chave: Criança. Escola. Tempo livre. Lazer.

\section{Abstract}

This study addresses children's after-school activities. This investigation belongs to the interdisciplinary field of leisure studies and seeks to better understand how children occupy time after school. Children aged nine to ten years old $(n=41)$, from two schools located in Belo Horizonte, Brazil, answered a semistructured interview. Answers were qualitatively examined through content analysis. Important differences highlighted children's free-time activities in public and private school. It is necessary to provide free and unstructured leisure experiences, especially in contexts that offer learning opportunities and social development for children.

Keywords: Child. School. Free time. Leisure.

1 Nota: Este trabalho relata o primeiro conjunto de dados inéditos de parte da dissertação de mestrado da primeira autora, sob orientação da segunda autora, do Programa de Pósgraduação Interdisciplinar em Estudos do Lazer (PPGIEL) da Universidade Federal de Minas Gerais (UFMG). Apoio: FAPEMIG, Fundep/Santander e PPG-Lazer/UFMG. Agradecimentos: E. Lourenço, A. C. G. Dias, L. C. Martins, T. L. de Carvalho, D. C. Silveira, escolas, pais e participantes.

Psicol. Argum. 2014 jul./set., 32(78), 67-78 


\section{Introdução}

0 presente trabalho apresenta um estudo sobre as atividades realizadas pelas crianças quando liberadas do período escolar. Trata-se de uma pesquisa que se insere no campo de estudos interdisciplinares do lazer e que busca conhecer melhor como crianças ocupam o tempo fora da escola. A este respeito, a literatura científica nacional tem se dedicado com afinco à discussão de como crianças com necessidades educativas especiais, em situação de risco ou enfrentando alguma patologia ocupam o tempo livre. Dessa forma, esta pesquisa espera contribuir para a produção científica sobre crianças sem vulnerabilidades explícitas como as referidas nesses trabalhos.

Em estudo conduzidonas cidades de Maringá e Belo Horizonte, Arruda e Müller (2010) e Debortoli et al. (2008), respectivamente, relataram que, ao andar pelos bairros onde suas pesquisas se desenrolaram, viram crianças brincando nas ruas das regiões mais pobres. Já a movimentação nos bairros de maior poder aquisitivo era quase nula, salvo em horários específicos como, por exemplo, o fim do horário escolar, no qual o tráfego de pessoas era maior, ou quando as babás levavam as crianças menores para praças. Já Njaine e Minayo (2004) relatam dados da pesquisa da UNICEF com 5.280 adolescentes brasileiros, dos quais $52 \%$ apontaram assistir televisão como sua maior fonte de lazer. Esses estudos evidenciam que as crianças passavam mais tempo em frente à televisão do que fazendo qualquer outra atividade, além de pouco utilizarem a rua como espaço para brincadeira.

Uma característica marcante da televisão, da internet e de alguns tipos de jogos de computador ou videogame é que estes meios de comunicação não oferecem à criança uma oportunidade para que seu processo criativo possa se manifestar de maneira plena. Cenários, situações e relações já vêm prontos nos jogos e nos programas de televisão, limitando a capacidade criativa da criança às opções oferecidas pelos mesmos (Oliveira, 2004). Além disso, um bombardeio de informações e estímulos se dá com tamanha velocidade que não possibilita o uso do tempo necessário para que os novos dados sejam assimilados e internalizados pelas crianças. Este fato exige delas uma resposta também rápida, que pode até ser vista como reação quase automática, e que não lhes permite questionar, analisar e, assim, formar seus próprios conceitos e opiniões, limitando sua curiosidade (Oliveira, 2004).

Na visão de Bondía (2002), a diminuição da capacidade de experienciar ou da possibilidade de vivenciar novos tipos de experiências, em virtude do volume de informações a que os indivíduos são expostos na atualidade, acaba por afastá-los da realidade na qual se inserem. Segundo Oliveira (2004), essa grande quantidade de informações pode atrapalhar a concentração e, consequentemente, o aprendizado das crianças. "O excesso de estímulos acaba por apagar a possibilidade criativa da criança, na medida em que não possibilita o tempo de suspensão necessário para a criação própria da brincadeira." (Meira, 2003, p.75). Assim, o próprio brincar é também prejudicado, pois pode passar a assumir características estereotipadas típicas das informações oferecidas por tais meios de comunicação.

Alguns autores podem argumentar em favor das novas formas de socialização com o advento da internet, mas os relacionamentos estabelecidos através da mesma não possibilitam o amadurecimento de características fundamentais à ocorrência de uma convivência saudável, como a resolução de conflitos. Uma vez contrariada, a criança pode simplesmente fechar o programa que esteja usando para se comunicar com outra pessoa e dessa maneira não aprenderá a dialogar ou negociar seus interesses. Oliveira (2004) diz ainda que a criança pode começar a reagir limitadamente quando se relaciona por esse meio, pois, por não possibilitar a observação das expressões e das respostas decorrentes de suas próprias ações, sua socialização pode se dar de maneira incompleta.

Segundo Njaine e Minayo (2004), algumas nações tem demonstrado maior preocupação científica na abordagem dos efeitos da mídia sobre crianças e adolescentes. Dados norte-americanos destacados por elas relatam efeitos sérios sobre a saúde infantil e adolescente, entre eles o aumento do comportamento violento, a obesidade, diminuição de atividades físicas e aptidões e prejuízo no desempenho escolar. Dados japoneses também indicam a relação estreita entre programação violenta na televisão e comportamentos violentos de crianças e adolescentes, mas atentam para variáveis familiares e individuais.

Njaine e Minayo (2004) focalizam o conteúdo violento da programação televisiva assistida por crianças e adolescentes brasileiros. No entanto, fornecem 
dados sobre o quanto esta atividade preenche o tempo livre do público em questão, ainda em fase de desenvolvimento físico, psicológico e social. Assim, é de interesse científico e social a atividade de assistir televisão por parte de crianças e adolescentes, não somente por seus efeitos diretos sobre a saúde como um todo, mas também pelas restritas oportunidades de experiências de lazer, por parte dessa mídia, que promovam felicidade e desenvolvimento pleno, com reflexos positivos à saúde.

0 brincar é uma das formas pelas quais as crianças se expressam, ou seja, sua forma de comunicação mais habitual utilizada para estabelecer relações com o mundo à sua volta, sempre repleto de envolvimento emocional e contato social. (Kishimoto, 2002). 0 brincar proporciona um momento propício para o exercício da imaginação e da criatividade, baseado na apropriação dos espaços e materiais disponíveis. (Arruda \& Müller, 2010). Assim, torna-se essencial a avaliação de como ele tem se manifestado nos dias de hoje e como isso influencia o desenvolvimento da criança, visto que é algo pertencente ao universo infantil.

Quanto à saúde das crianças, há algum tempo vem sendo discutidos problemas como a obesidade infantil, em especial a baixa frequência de atividades físicas e a alimentação inadequada proporcionada às crianças. Dois estudos recentes e com amostras representativas relatam estes problemas.

Molina, Faria, Montero, Cade e Mill (2010) avaliaram dados antropométricos, de pressão arterial, consumo alimentar e tempo diário de lazer sedentário (até quatro horas diárias) em 1.282 crianças de sete a dez anos de idade moradoras da cidade de Vitória (Espírito Santo). 0 fator de risco cardiovascular mais frequente nas crianças estudadas foi 0 lazer sedentário (soma das horas gastas com videogame, computador e televisão), presente em 53,8\% dos meninos e em $45 \%$ das meninas participantes do estudo. Portanto, estudos realizados com foco na saúde cardiovascular infantil como esse não devem deixar de incluir, além das variáveis tradicionais, aquelas referentes ao estilo de vida da criança, como as atividades que desempenha em seu cotidiano. 0 trabalho de Molina et al. (2010) mostra, sobretudo, a grande incidência de atividades de lazer infantil que envolvem televisão, computador e videogame, e o risco associado à saúde da criança.

Bergmann et al. (2011) abordaram 1.294 crianças de sete a doze anos da cidade de Caxias do Sul
(Rio Grande do Sul) sobre hábitos alimentares, de atividade física e de lazer, e mediram o colesterol total, massa corporal e aptidão cardiorrespiratória. Das crianças participantes, $61,3 \%$ não praticam esporte no tempo de lazer, 30,2\% passam mais de três horas com a televisão, videogame ou computador, e $62,2 \%$ possuem baixa aptidão cardiorrespiratória. As crianças de nível socioeconômico mais alto, de sexo feminino, e com excesso de peso apresentam mais riscos ao colesterol total acima do nível esperado. Além de confirmar dados amplamente divulgados sobre o aumento da massa corporal de crianças brasileiras, essa pesquisa mostra a relevância de se considerar o nível socioeconômico da criança como indicativo de risco à sua saúde em virtude do estilo de vida que leva. Maior acesso a tecnologias como computador e videogame, por exemplo, alteram a preferência por determinadas atividades fora da vida escolar e acarretam alterações importantes na saúde da criança.

Dada a relevância das atividades infantis fora do período escolar, especialmente pelo aumento da preferência por atividades envolvendo televisão, computador e videogame e seus reflexos sobre a saúde física da criança, foi conduzido o presente estudo. 0 objetivo principal foi conhecer e descrever as atividades das crianças fora do horário de aula, espaços utilizados, companhias, preferências, sentimentos e importância dessas atividades na visão das crianças.

\section{Método}

0 presente trabalho apresenta características tanto de abordagem quantitativa como qualitativa. Trata-se de um estudo de delineamento descritivo e exploratório, com amostragem por conveniência, visto que não foram almejadas generalizações a partir dos resultados.

Participaram do estudo 41 crianças (50\% meninas) com idade entre 9 e 10 anos, metade delas cursando o quinto ano do ensino fundamental no turno da manhã em uma escola pública, e metade em uma escola privada. As escolas se localizam na mesma região da cidade de Belo Horizonte, Minas Gerais, o que significa que as escolas compartilham os mesmos espaços e equipamentos de lazer (parques, praças, cinemas, lagoa etc.).

Psicol. Argum. 2014 jul./set., 32(78), 67-78 
Crianças estudantes do turno da manhã foram convidadas por terem mais tempo liberado do horário escolar, visto que muito provavelmente as crianças do turno da tarde gastam parte da manhã dormindo. Em relação ao nível socioeconômico, foi feita uma aproximação a esta variável ao serem selecionadas uma escola pública e uma privada, com base no valor da mensalidade da escola privada.

As crianças foram sorteadas a partir das listas de turmas e convidadas a responder uma entrevista semiestruturada individual nas dependências da escola. 0 objetivo da entrevista foi acessar as descrições das atividades realizadas durante o período liberado da jornada escolar, indicando, entre outros aspectos, sentimentos associados às atividades, companhias, espaços utilizados, atividades preferidas e importância das atividades. As entrevistas foram gravadas em áudio e posteriormente transcritas para análise.

Duas avaliadoras treinadas executaram a análise das respostas das crianças às entrevistas através da construção de categorias com base em unidades temáticas semelhantes em sentido, inspiradas nos princípios da análise de conteúdo (Bardin, 2011). Foram calculadas frequências das respostas nas categorias, apontando-se o gênero das crianças e o tipo de escola (pública ou privada). As avaliadoras reuniram os conteúdos afins e formaram agrupamentos temáticos de modo independente. Posteriormente, compararam ambas as classificações para a decisão final sobre os agrupamentos temáticos em categorias. Diante de dúvidas no processo de categorização, um terceiro avaliador foi consultado. 0 trabalho foi aprovado pelo comitê de ética local sob o parecer 0185.0.203.000-10.

\section{Resultados}

Inicialmente, cabe mencionar que nem todas as crianças responderam a todas as perguntas. Algumas delas se mostraram tímidas e limitaram a resposta a poucas palavras, outras forneceram respostas evasivas ou repetitivas, e mesmo com o estímulo de perguntas diferentes, saturavam suas respostas. Assim, o total indicado nas tabelas corresponde à frequência de entrevistados que explicitamente mencionaram realizar a atividade.

As respostas das crianças às perguntas 1 e 2 da entrevista foram analisadas conjuntamente por sua similaridade de conteúdo. A Tabela 1 mostra a frequência das respostas das crianças entrevistadas em relação ao que fazem quando não estão em horário escolar.

As categorias com frequência menor que 4 respostas, ou seja, com frequência inferior a $10 \%$ do total da amostra, foram as seguintes: estudar; "escolinha da Igreja"; viajar; "escola integrada"; conversar; "reforço escolar"; "aula de culinária"; "aula de boas maneiras"; voluntariado; "escrever música"; passear; "ajudar o pai com seu serviço"; e "acompanhar a mãe no trabalho". Com respeito às respostas que envolvem o uso da bola e futebol, em virtude das explicações das crianças, estas respostas foram assim agrupadas: a) brincar de/com bola e jogar bola: brincadeira livre que pode se caracterizar como passar a bola de uma pessoa para outra ou contra a parede, caso a criança esteja brincando sozinha; b) futebol (jogar/futebol): jogo mais estruturado, com uso de regras; c) aula de futebol: aulas especializadas fora do horário escolar.

A categoria "brincar de esportes" incluiu respostas sobre brincadeiras baseadas em peteca, basquete, handebol, vôlei etc. A fala da criança sempre iniciava como "eu brinco de...". Já a "aula de outros esportes" envolvia aulas estruturadas desenvolvidas fora do horário da educação formal (handebol, tênis, judô e ginástica rítmica). As "brincadeiras físicas" demandavam maior esforço físico, como "amarelinha", "pular na cama", pular corda, "queimada", ou "pique no alto". Por "relação com animais", pretendeu-se agrupar respostas como passear com cachorro e cuidar/ brincar com animais (cachorro, galinha). Por fim, as "outras brincadeiras", que não integraram as categorias anteriormente formadas, foram: fazer castelo, "brincar de areia", "montar coisas com brinquedos quebrados", "jogo da televisão de montar" e "brincar com prêmio que eu ganho".

Como mostra a Tabela 1, as crianças da escola privada citaram mais atividades com uso de computadores e videogames, que demandam determinada renda familiar. Somente as crianças da escola particular nomeavam a marca do videogame que jogavam. Ao mesmo tempo, é possível perceber que em algumas das atividades que exigem maior esforço motor como brincar de bola, pega-pega, brincadeiras ao ar livre ou físicas, prevaleceram crianças da escola pública. Interessantemente, as meninas de escola pública foram as únicas a ocupar a categoria trabalho doméstico. 
Tabela 1: Frequência de respostas de atividades no tempo livre da escola, por gênero e escola

\begin{tabular}{|c|c|c|c|c|c|}
\hline \multirow{2}{*}{ Atividade } & \multicolumn{2}{|c|}{ Gênero } & \multicolumn{2}{|c|}{ Escola } & \multirow{2}{*}{$\begin{array}{c}\mathbf{f} \\
\text { Total }\end{array}$} \\
\hline & $\mathbf{F}$ & $\mathbf{M}$ & Pública & Privada & \\
\hline ver telelevisão & 14 & 16 & 14 & 16 & 30 \\
\hline fazer o "para casa" & 17 & 10 & 11 & 16 & 27 \\
\hline computador & 8 & 10 & 11 & 16 & 27 \\
\hline videogame & 4 & 13 & 6 & 11 & 17 \\
\hline brincar de/com bola e jogar bola & 7 & 7 & 9 & 5 & 14 \\
\hline brincar de esconde-esconde & 5 & 6 & 5 & 6 & 11 \\
\hline dormir/descansar & 3 & 8 & 5 & 6 & 11 \\
\hline brincar de boneca & 10 & 0 & 7 & 3 & 10 \\
\hline brincar com brinquedos & 3 & 5 & 4 & 4 & 8 \\
\hline brincar de pega-pega/pegador & 4 & 4 & 5 & 3 & 8 \\
\hline serviços domésticos & 8 & 0 & 8 & 0 & 8 \\
\hline brincar de faz de conta & 6 & 1 & 5 & 2 & 7 \\
\hline aula de futebol/futsal & 1 & 6 & 1 & 6 & 7 \\
\hline brincar de jogos & 5 & 1 & 2 & 4 & 6 \\
\hline brincar de esportes & 3 & 3 & 3 & 3 & 6 \\
\hline futebol (jogar) & 2 & 4 & 0 & 6 & 6 \\
\hline assistir filme/DVD & 2 & 4 & 3 & 3 & 6 \\
\hline soltar papagaio/pipa & 2 & 4 & 6 & 0 & 6 \\
\hline aula de natação & 4 & 2 & 1 & 5 & 6 \\
\hline aula de outros esportes & 3 & 3 & 0 & 6 & 6 \\
\hline andar de bicicleta & 4 & 2 & 3 & 3 & 6 \\
\hline relação com animais & 3 & 3 & 2 & 4 & 6 \\
\hline brincadeiras ao ar livre & 4 & 1 & 4 & 1 & 5 \\
\hline brincadeiras físicas & 2 & 3 & 5 & 0 & 5 \\
\hline outras brincadeiras & 2 & 3 & 3 & 2 & 5 \\
\hline brincar de carrinho & 2 & 3 & 4 & 1 & 5 \\
\hline aula de línguas & 5 & 0 & 0 & 5 & 5 \\
\hline aula de balé & 5 & 0 & 1 & 4 & 5 \\
\hline aula de instrumentos musicais & 3 & 1 & 0 & 4 & 4 \\
\hline ler & 3 & 1 & 2 & 2 & 4 \\
\hline
\end{tabular}

Notas: $\mathrm{f}=$ frequência; $\mathrm{F}=$ feminino; $\mathrm{M}$ = masculino.

A Tabela 2 mostra os espaços das vivências do tempo livre da escola. As categorias com baixa frequência de respostas foram: parque, clube, sítio/ fazenda, ir a festas, "feira do Mineirinho" (ginásio), brincar na casa da filha da amiga da mãe, ir para casa de amigos dos pais, ir ao médico, sair de casa para jogar futebol com amigos, sair para almoçar, "frequentar centro espírita".

É possível perceber que muitas das práticas desenvolvidas durante o horário liberado da escola têm acontecido em espaços limitados como casas/ apartamentos ou áreas externas a prédios. Nota-se também que as respostas mais frequentes relacionadas a práticas que envolvem deslocamento espacial são de crianças da escola particular.

A Tabela 3 mostra as companhias envolvidas nas práticas fora do horário escolar. A categoria "sair com pai/mãe" diz respeito a práticas como ir ao shopping, "ir ao salão de beleza esperar a mãe", "ir ao trabalho do pai/mãe" ou sair com o pai para buscar a mãe no trabalho. As respostas com frequência inferior a quatro foram: vizinhos, sozinho(a), família (ficar em casa, pedir pizza e alugar filme), sair para almoçar com família, futebol com tios.

Psicol. Argum. 2014 jul./set., 32(78), 67-78 
Tabela 2: Frequência de respostas sobre espaço das atividades, por gênero e escola

\begin{tabular}{|c|c|c|c|c|c|}
\hline \multirow{2}{*}{ Espaço } & \multicolumn{2}{|c|}{ Gênero } & \multicolumn{2}{|c|}{ Escola } & \multirow{2}{*}{$\frac{\mathbf{f}}{\text { Total }}$} \\
\hline & $\mathbf{F}$ & $\mathbf{M}$ & Pública & Privada & \\
\hline brincar em casa/apartamento & 5 & 4 & 7 & 2 & 9 \\
\hline receber amigos, colegas, vizinhos, primos em casa & 3 & 5 & 2 & 6 & 8 \\
\hline casa de parentes & 4 & 3 & 3 & 4 & 7 \\
\hline casa de vizinhos, colegas e amigos & 3 & 4 & 1 & 6 & 7 \\
\hline terreiro, quintal, playground no prédio & 4 & 1 & 2 & 3 & 5 \\
\hline brincar na rua ou "lá fora" & 1 & 3 & 2 & 2 & 4 \\
\hline
\end{tabular}

Notas: $\mathrm{f}$ = frequência; $\mathrm{F}$ = feminino; $\mathrm{M}$ = masculino.

Tabela 3: Frequência de respostas sobre companhias nas atividades livres da escola, por gênero e escola

\begin{tabular}{lccccc}
\hline \multirow{2}{*}{ Companhia } & \multicolumn{2}{c}{ Gênero } & \multicolumn{2}{c}{ Escola } & $\mathbf{f}$ \\
\cline { 2 - 7 } & $\mathbf{F}$ & $\mathbf{M}$ & Pública & Privada & Total \\
\hline irmãos & 8 & 5 & 7 & 6 & 13 \\
amigos & 5 & 3 & 2 & 6 & 8 \\
primos & 2 & 5 & 4 & 3 & 7 \\
sair com pai/mãe & 3 & 3 & 1 & 5 & 6 \\
colegas & 2 & 2 & 3 & 1 & 4 \\
pais/avós & 1 & 3 & 1 & 3 & 4 \\
\hline
\end{tabular}

Notas: $\mathrm{f}$ = frequência; $\mathrm{F}$ = feminino; $\mathrm{M}=$ masculino.

Tabela 4: Frequência de respostas sobre atividades preferidas, por gênero e escola

\begin{tabular}{|c|c|c|c|c|c|}
\hline & \multicolumn{2}{|c|}{ Gênero } & \multicolumn{2}{|c|}{ Escola } & \multirow{2}{*}{$\begin{array}{c}\text { f } \\
\text { Total }\end{array}$} \\
\hline & $\mathbf{F}$ & $\mathbf{M}$ & Pública & Privada & \\
\hline Uma atividade preferida & & & $\mathbf{n}=\mathbf{2 8}$ & & \\
\hline videogame/computador & 3 & 3 & 2 & 4 & 6 \\
\hline futebol & 0 & 5 & 1 & 4 & 5 \\
\hline aulas formais & 4 & 1 & 2 & 3 & 5 \\
\hline brincadeiras & 3 & 2 & 4 & 1 & 5 \\
\hline Duas ou três atividades & & & $n=13$ & & \\
\hline aulas formais & 4 & 2 & 0 & 6 & 6 \\
\hline brincadeiras & 5 & 0 & 1 & 4 & 5 \\
\hline videogame/computador & 2 & 2 & 2 & 2 & 4 \\
\hline
\end{tabular}

Notas: $\mathrm{f}$ = frequência; $\mathrm{F}$ = feminino; $\mathrm{M}$ = masculino.

As atividades preferidas das crianças fora do período escolar são apresentadas na Tabela 4, que especifica as crianças que elegeram uma única atividade favorita ( $\mathrm{n}=28$ ), e aquelas que indicaram duas ou três $(n=13)$. As "aulas formais" dizem respeito a aulas estruturadas, com professor, de futebol, inglês, balé, natação etc., enquanto as "brincadeiras" agruparam respostas como brincar, brincar com amigos, com cachorro, com Barbie e pular corda. As crianças que indicaram uma atividade favorita também mencionaram as seguintes, com baixa frequência: ver televisão, jogar bola, ir ao shopping com a mãe, ajudar a mãe, jogar paintball; as que indicaram duas ou três citaram: ver televisão, jogar futebol, jogar bola, andar de bicicleta, ler, atividades relativas à escola, jogar tênis e ir ao parque de diversões.

A Tabela 5 mostra as companhias indicadas pelas crianças na realização da(s) atividade(s) favorita(s). As respostas com pouca frequência foram: companheiro de balé, professores e empregada doméstica.

Quanto à importância atribuída às atividades realizadas no horário liberado da escola, 30 julgaram 
Tabela 5: Frequência de respostas sobre companhias nas atividades preferidas

\begin{tabular}{|c|c|c|c|c|c|}
\hline \multirow{2}{*}{ Companhia } & \multicolumn{2}{|c|}{ Gênero } & \multicolumn{2}{|c|}{ Escola } & \multirow{2}{*}{$\frac{\mathbf{f}}{\text { Total }}$} \\
\hline & $\mathbf{F}$ & M & Pública & Privada & \\
\hline amigos & 5 & 6 & 2 & 9 & 11 \\
\hline pais & 2 & 6 & 4 & 4 & 8 \\
\hline primos & 1 & 7 & 5 & 3 & 8 \\
\hline colegas & 2 & 3 & 4 & 1 & 5 \\
\hline irmãos & 2 & 3 & 0 & 5 & 5 \\
\hline sozinho & 2 & 3 & 4 & 1 & 5 \\
\hline vizinhos & 1 & 3 & 4 & 0 & 4 \\
\hline
\end{tabular}

Notas: $\mathrm{f}$ = frequência; $\mathrm{F}$ = feminino; $\mathrm{M}=$ masculino.

Tabela 6: Frequência de respostas sobre motivos da importância das atividades, por gênero e escola

\begin{tabular}{lccccc}
\hline \multirow{2}{*}{ Motivo } & \multicolumn{2}{c}{ Gênero } & \multicolumn{2}{c}{ Escola } & f \\
\cline { 2 - 6 } & F & M & Pública & Privada & Total \\
\hline preocupação com saúde/bem estar & 7 & 6 & 3 & 10 & 13 \\
preocupação com o futuro & 4 & 4 & 4 & 4 & 8 \\
diversão/gosto/alegria & 5 & 2 & 2 & 5 & 7 \\
porque gosta & 3 & 2 & 3 & 2 & 5 \\
melhoria do aprendizado/desempenho escolar & 1 & 4 & 2 & 3 & 5 \\
para aprender & 3 & 1 & 2 & 2 & 4 \\
valor do brincar na infância & 4 & 0 & 2 & 2 & 4 \\
bom para saúde/ corpo/ é saudável & 2 & 2 & 2 & 2 & 4 \\
para ajudar outros & 4 & 0 & 4 & 0 & 4 \\
\hline
\end{tabular}

Notas: $\mathrm{f}$ = frequência; $\mathrm{F}$ = feminino; $\mathrm{M}=$ masculino.

importante, 6 manifestaram que algumas são importantes, 4 não acham as atividades importantes e 1 respondeu "não sei". Do total, 35 crianças apontaram os motivos pelos quais acreditam que a prática de tais atividades seja importante. A Tabela 6 mostra esses resultados. As respostas pouco frequentes foram: proporciona relações sociais; "para se comunicar"; "ganhar coisas"; "o cachorro precisa passear"; "fazer compras para ter comida"; "evitar vícios de computador". As respostas sobre preocupação com saúde e bem-estar possuíam conteúdos como: "porque gasta energia/caloria"; "brincar faz bem para o coração"; são atividades físicas e dão energia pra fazer outras coisas; "porque se não começa a engordar". As respostas sobre preocupação com futuro envolveram conteúdos como: "para arrumar bom serviço/emprego"; "para ser jogador de futebol quando crescer"; "para saber fazer quando crescer". Sobre o valor do brincar na infância, as crianças manifestaram os seguintes motivos: porque a infância passa muito rápido, porque vai ser difícil brincar quando for mais velha, porque pode brincar mais, ter mais tempo pra brincar. As respostas sobre "proporciona relações sociais" citaram as seguintes razões: para ter a companhia da mãe depois de ajudá-la, porque quando precisar de ajuda vai ter amigos. Já a resposta "para poder se comunicar" abarcava o aprendizado de línguas estrangeiras.

Foi pedido às crianças que apontassem qual a atividade mais importante, e 25 participantes responderam. Sete respostas abordaram futebol, quatro reuniram outras atividades esportivas (natação, ginástica rítmica, esporte (geral), escola de futebol), e as demais respostas envolveram os seguintes conteúdos: atividades relacionadas à escola (ir para a escola, fazer o "para casa"), arrumar a casa, brincar, balé, inglês, "obedecer à mãe/vó" e ir ao shopping. Outras quatro crianças elegeram duas atividades mais importantes (entre elas natação, escola integrada e serviços voluntários em outra escola, assistir televisão, "brincar de bola", aulas de inglês e estudar).

A Tabela 7 mostra os resultados da análise das respostas dos participantes à pergunta cinco da

Psicol. Argum. 2014 jul./set., 32(78), 67-78 
Tabela 7: Frequência de respostas de sentimentos sobre participação nas atividades, por gênero e escola

\begin{tabular}{lccccc}
\multirow{2}{*}{ Sentimento } & \multicolumn{2}{c}{ Gênero } & \multicolumn{2}{c}{ Escola } & f \\
\cline { 2 - 6 } & $\mathbf{F}$ & $\mathbf{M}$ & Pública & Privada & Total \\
\hline feliz & 10 & 8 & 4 & 14 & 18 \\
bem & 7 & 4 & 7 & 4 & 11 \\
alegre & 3 & 5 & 7 & 1 & 8 \\
legal & 2 & 2 & 3 & 1 & 4 \\
cansaço como consequência & 1 & 3 & 0 & 4 & 4 \\
\hline
\end{tabular}

Notas: $\mathrm{f}$ = frequência; $\mathrm{F}$ = feminino; $\mathrm{M}$ = masculino.

entrevista, que procurou descobrir como as crianças se sentiam ao realizar as atividades no tempo livre da escola. Sentimentos positivos e de bem-estar prevaleceram como resposta: feliz, bem e alegre. As respostas com frequência inferior a quatro foram: sentimentos negativos (nervosismo, tédio, solidão), "normal", "como se estivesse se apresentando em público", saudável, "cheia de energia e querendo mais", "com vontade de mais", "eu aprendo", criativo, mais solto, orgulho e "me acho quase adulta". Segundo as entrevistas, os sentimentos negativos são consequência de atividades específicas como a digitação (a criança fica nervosa, com medo de errar), videogame (tédio) e o brincar sozinha (solidão). 0 cansaço relatado é físico, decorrente de atividades como a natação, correr e jogar bola.

Além da resposta de como se sentiam, 11 crianças espontaneamente justificaram o sentimento. Oito crianças justificaram como "porque é bom para mim", ou seja, porque é algo que gosta de praticar/ fazer; "é coisa boa para mim"; "porque eu quero"; "porque é bom de brincar"; "por ser minha coisa preferida"; "porque todos torcem por mim e isso me motiva a fazer coisas melhores". Quatro crianças afirmaram que "é porque é bom para os outros": "porque é legal ajudar a mãe", "porque quando a mãe chegar ela vai poder descansar" e "porque sei que estou fazendo uma coisa boa para a família". Outras duas respostas justificaram da seguinte forma: "porque é (tipo) uma brincadeira" e "porque fica correndo e faz exercícios".

Em resumo, a análise dos resultados mostrou que: 1) as quatro atividades mais citadas pelas crianças como realizadas no tempo liberado da escola são: ver televisão, fazer o "para casa", usar o computador (também para brincar, jogar) e jogar videogame; 2) os espaços mais citados foram o próprio lar da criança, receber outras crianças em casa, casa de parentes e casa de outras crianças; 3 ) as companhias mais frequentes nas atividades fora do horário escolar são de irmãos, amigos e primos; 4) fora do horário da escola, as atividades preferidas envolvem uso do videogame e computador, futebol, outras aulas (fora da escola) e brincadeiras; 5) amigos, pais e primos são as companhias mais frequentes nas atividades preferidas; 6) as atividades fora do horário da escola são importantes para a saúde, bem-estar, futuro e porque proporcionam emoções positivas; 7) em termos de eleição da atividade mais importante, as atividades mais citadas pelas crianças foram futebol e outros esportes; 8) sentimentos de bem-estar, felicidade e alegria são vivenciados pelas crianças nas atividades fora do horário da escola por serem boas para elas ou para outras pessoas.

\section{Discussão}

As quatro atividades realizadas com maior frequência no tempo liberado da escola das crianças participantes desta pesquisa têm como ponto em comum o sedentarismo e o fato de acontecerem em espaços fechados. Assistir televisão, fazer o dever de casa e utilizar computadores e videogames, além de impedirem que as crianças se movimentem, pouco servem como fonte de estímulos para a construção de sua autonomia. De acordo com Oliveira (2004), para que possa se desenvolver plenamente, a criança necessita brincar livremente e movimentar todos os seus músculos, pois a liberdade no ato de brincar permite a ela explorar velocidades, texturas, ruídos, limites etc. em função das dificuldades impostas pelo ambiente. É possível pensar que tal objetivo seria alcançado com a participação em atividades dirigidas, como aulas de dança, ginástica ou futebol. 
No entanto, segundo Oliveira (2004), tais movimentos não seriam suficientemente estimulados por atividades esportivas programadas. A brincadeira livre seria assim responsável pela construção de si mesmo enquanto sujeito social através das relações, fazendo de quem brinca um conhecedor de suas próprias habilidades e limitações. (Debortoli, 2002; Nunes \& Becker, 2000).

0 tempo gasto com essas atividades parece ter um destaque especial na maneira como as crianças preenchem seu tempo liberado da escola. Entre outros aspectos, a pesquisa mostrou certa insatisfação, principalmente por parte das crianças da escola particular, em relação ao tempo gasto com o cumprimento de seus deveres de casa. Muitas dessas crianças disseram que ficam uma boa parte de seu dia por conta do "para casa e que a quantidade de atividades que as professoras mandam como dever acaba por tirar grande parte do seu tempo de brincar, dizendo inclusive que brincam quando "sobra" tempo depois de terem concluído seus exercícios escolares ou suas atividades extraclasse. 0 trabalho mostrou também que algumas crianças classificam o brincar no computador/videogame ou o assistir televisão como atividades preferidas, e que por isso passam todo o tempo que podem realizando tais atividades.

A realidade de restrição de movimentos, na qual muitas das crianças entrevistadas estão inseridas, seja pela escolha das atividades a serem realizadas, seja por não poderem sair de casa frequentemente (falta de supervisão adulta ou por motivos de segurança) pode trazer consequências sociais por estimularem isolamento. 0 espaço fechado onde desenvolvem essas práticas, como seu próprio quarto ou um cantinho de brincar improvisado dentro das residências (estas cada vez menores), "além de ser um espaço reduzido, é estático e pouco mutável, onde dificilmente surgem novas informações e fatores que sejam fonte de estímulos. A criança fica isolada, sem companhia para brincar e compartilhar suas experiências comuns". (Oliveira, 2004, p. 176).

No caso das atividades com uso de computadores/videogame e televisão, alguns estímulos ainda continuam a aparecer, mas eles se limitam a determinados tipos como os cognitivos, auditivos e os visuais, ainda em prejuízo dos estímulos físicos e sociais. Dessa maneira, é plausível pensar que a exposição destes indivíduos a situações de aprendizado através do convívio com as diferenças em seu cotidiano é possivelmente menor que aquele de crianças que possuem experiências mais presenciais de contato com seus pares. Estas experiências presenciais podem colaborar para aumentar o repertório de habilidades sociais da criança, preparando-a melhor para eventuais conflitos interpessoais.

De maneira geral, a participação dos alunos da escola privada prevalece em atividades de baixa movimentação corporal, enquanto aqueles da escola pública predominam em atividades que demandam grandes esforços físicos e que sejam realizadas ao ar livre. Brincadeiras como jogar bola, pega-pega e empinar pipa foram mais citadas pelas crianças de escola pública, ao passo que as atividades que demandam certo poder aquisitivo, como jogar videogame e brincar no computador, foram mencionadas majoritariamente pelas crianças da escola particular. Esses resultados vão ao encontro dos de Bergmann et al. (2011), que encontraram maior índice de risco à saúde nas crianças de nível socioeconômico alto.

A esse respeito, a discrepância observada entre os tipos de atividades realizadas por cada grupo de crianças pode ser associada às mudanças sociais que "fazem-se acompanhar também de mudanças nas culturas de infância e mais particularmente no consumo cultural do lazer". (Neto, 2000, p. 1). Nesse sentido, é curioso observar que diferentes termos são utilizados pelos dois grupos de entrevistados para se referir à prática de jogar videogame. Das 17 crianças que disseram realizar esta atividade em seu tempo liberado da escola, 11 participantes da escola particular nomearam com qual aparelho de videogame brincavam, enquanto os 6 alunos da escola pública usaram o termo genérico "videogame". Os dados apresentados sugerem que a diferença entre os termos utilizados pelas crianças da escola particular para se referir aos jogos eletrônicos evidencia um status, tendo em vista que, quanto maior o poder aquisitivo, maior é a possibilidade de compra de aparelhos de última geração. Segundo Debortoli et al. (2008, p. 31) "na sociedade e cultura do consumo, a aparência e os símbolos de status se fazem presentes o tempo todo".

Ainda sobre os aspectos socioeconômicos que influenciam no tipo de brincadeira realizada pelas crianças, Müller, Rodrigues, Ribeiro e Pelegrini (2007, p.1) afirmam que

Psicol. Argum. 2014 jul./set., 32(78), 67-78 
nos cotidianos infantis de pobres e ricos há, entre outras, esta diferença: na hora de brincar, uns brincam com o que desejam brincar, e os outros brincam com o que tem e, principalmente, com o que não tem. Imaginam, inventam... Na brincadeira da criança há o reflexo da (in)capacidade de compra da família.

Esta afirmação das autoras corrobora com o dado encontrado por esta pesquisa que mostra que das 7 crianças que afirmaram brincar de faz de conta, 5 eram da escola pública. Talvez por esta razão seja possível levantar uma hipótese de que, por não disporem de tantos materiais para brincar, as crianças de nível socioeconômico mais baixo tenham sua criatividade mais estimulada.Vale a pena mencionar também a exclusão digital mostrada pelos dados, através dos quais se pode perceber que, das 18 crianças que disseram fazer uso do computador, somente 4 eram da escola pública. Tal dado traz à luz o fato de não existirem suficientes lugares públicos onde o acesso a computadores e à internet estejam ao alcance de todos, o que acaba por reforçar ainda mais as diferenças socioeconômicas existentes. Segundo Silva Junior, Tolocka e Marcellino (2006, p.88), o acesso a estes meios de comunicação ofereceria "melhores condições de desenvolvimento dos cidadãos como indivíduos e da comunidade como sociedade, e o indivíduo que não tiver acesso e/ou não se adaptar a esses equipamentos, poderá perder boas oportunidades de trabalho, de estudo e de lazer".

Existe uma série de leis que procuram garantir os direitos das crianças e dos adolescentes, entre eles o lazer. Apesar de essas leis serem reconhecidas e amplamente reforçadas por diversas instituições, muitas das mudanças sociais características das últimas décadas tem diminuído as possibilidades da vivência plena do lazer (seja por crianças ou adultos), especialmente o lazer de interesse físico (Silva Junior et al., 2006). Fatores como violência, valorização territorial, crescimento demográfico e da frota de transportes urbanos e tempo de trabalho têm se apresentado como barreiras à realização de jogos motores, tão importantes para o desenvolvimento infantil (Debortoli et al., 2008; Silva Junior et al., 2006).

Ao andar pelas cidades é possível observar que sua arquitetura mudou, e com ela a quantidade de pessoas que se encontravam nas ruas. Apesar de parecer contraditório, a estabilidade econômica tem estimulado uma insegurança social, principalmente nas classes de maior poder aquisitivo, evidenciada pelo deslocamento dessa população para bairros concebidos como "refúgios" alternativos à desorganização e aos perigos oferecidos pelos centros, que enfatizam ainda mais a distância relacional entre os distintos extratos da sociedade moderna. (Debortoli et al., 2008). 0 que se vê também é que, em virtude de tais mudanças, especialmente da violência, muitas práticas de lazer começaram a ser desenvolvidas nas próprias residências (televisão, videogame, almoço em família etc.), independentemente da classe social.

Os dados da presente pesquisa apontam que o espaço no qual são realizadas as práticas do tempo liberado da escola das crianças é o lar, seja das próprias crianças, seja de seus pares ou parentes. Mostram também que as atividades desenvolvidas pelas crianças, principalmente durante a semana, em espaços públicos como ruas ou parques, não tiveram coro suficiente para formar categoria. Duas práticas de lazer mais frequentes realizadas por elas, assistir televisão e descansar, são também desenvolvidas em residências.

Arruda e Müller (2010), utilizando-se de técnicas etnográficas para investigar sobre o brincar de crianças de dois bairros de diferentes níveis socioeconômicos da cidade de Maringá (PR), observaram que uma característica do brincar das crianças mais pobres era a coletividade, pois foram observadas constantemente brincando em grupos. Este fato faz oposição às brincadeiras mais individuais realizadas pelas crianças mais ricas. Reconhece-se a importância do brincar sozinho no desenvolvimento infantil, mas o que deve ser levado em consideração por suas possíveis consequências é o brincar solitário, sem parceiros ou coletividade, como algo constante no cotidiano da criança.

Faz sentido pensar que por terem seus espaços de circulação drasticamente reduzidos, as possibilidades de socialização também passaram a ser mais raras. A questão espacial pode estar diretamente ligada à quantidade de crianças disponíveis para brincar. Ainda que deva ser levada em conta a diferença na terminologia utilizada pelas crianças (amigos ou colegas), os dados desta pesquisa mostram que as crianças da escola particular brincam mais com seus pares que as da escola pública. Apesar desses dados, a literatura tem mostrado o contrário a respeito dessa classe (Debortoli et al., 2008), mas 
é possível que tal diferença seja causada pelo tamanho reduzido da amostra do presente trabalho, logo não representativa.

Na mesma direção do trabalho de Arruda e Müller (2010) e de Debortoli et al. (2008), os dados do presente trabalho mostram que as crianças da escola pública mais frequentemente realizavam brincadeiras ao ar livre, apropriando-se de lugares de uso coletivo, como ruas e praças. Já muitas das práticas de lazer dos estudantes da escola particular eram desenvolvidas em shoppings, clubes, parques etc. Dessa maneira, é possível entender que, para as classes socioeconômicas mais favorecidas, os espaços para a vivência do lazer são preestabelecidos e determinados por usos específicos, uma prática mais controlada e menos espontânea, com estreita relação com a cultura do consumo. (Debortoli et al., 2008).

As crianças da escola pública foram as que mais relataram brincadeiras na rua. Segundo Debortoli et al. (2008), ao contrário da regulação característica de alguns dos espaços de lazer frequentados por famílias mais abastadas, a precariedade de infraestrutura voltada especificamente para o lazer nos bairros mais pobres faz com que seus habitantes, especialmente as crianças, se apropriem de seus arredores e espaços livres de maneira alternativa, reconstruindo-os e dando a eles novas funções e significados, inventando novos tipos de brincadeiras. De acordo com Oliveira (2004, p. 175), o maior atrativo percebido por elas nas ruas "decorria do fato das crianças poderem realizar informalmente e com liberdade seus divertimentos, criações, e o aprendizado mental, emocional, corporal e social para construção de sua autonomia".

As brincadeiras de rua são hoje, em muitos casos, realizadas com a supervisão de adultos devido aos perigos iminentes. Algumas das crianças entrevistadas de ambas as escolas relataram ter vontade de brincar em espaços mais amplos, mas justificaram a não possibilidade de concretização desse desejo por não terem a companhia de um adulto. Entre os perigos oferecidos pelas ruas, o aumento do número de carros que circula pelas cidades diminuiu em muito os espaços disponíveis para a socialização e a livre movimentação de crianças e adolescentes. (Silva Junior et al., 2006).

Outro aspecto importante diz respeito às novas formas de relacionar-se com o tempo estimuladas principalmente pelas mudanças nas relações com o trabalho. (Bondía, 2002). A noção de tempo das crianças da escola particular parece ser diferente daquela das crianças da escola pública, especialmente em função das atividades com as quais se envolvem fora do horário escolar. Muitas relataram o que fazem quando não estão na escola de acordo com o dia da semana e também descreveram seu tempo liberado (tarde e noite) de maneira mais detalhada, especificando horas bastante demarcadas para a realização de seu para casa, de descanso e até do tempo para brincar. Algumas relataram épocas passadas em que sua agenda estava muito cheia e que tinham que fazer o para casa à noite, quando chegavam em casa. Segundo Neto (2000, p. 1), "o tempo espontâneo, da imprevisibilidade, da aventura, do risco, do confronto com o espaço físico natural, deu lugar ao tempo organizado, planeado, uniformizado", isto é, um "tempo livre institucionalizado".

Observa-se nas entrevistas que muitas crianças baseiam seu tempo de acordo com os horários de trabalho dos pais. Há relatos em que elas dizem ir dormir após a chegada destes em casa ou que deixam de fazer coisas que gostariam, pois eles estão no trabalho. Segundo Müller et al. (2007, p.1),

o tempo ocupado de muitas crianças é o mesmo tempo de trabalho dos pais... As crianças estão levando uma vida muito determinada pelos adultos, por suas relações de trabalho, por sua necessidade de sobrevivência e, portanto, por tudo o que implicam suas diferentes classes sociais.

Muitos autores (Debortoli et al., 2008; Müller et al., 2007; Neto, 2000) têm discorrido sobre um processo de institucionalização da vida cotidiana da infância contemporânea, seja por sua participação em atividades formais, como a escola, e as não formais, como as entidades promotoras de oficinas (Müller et al., 2007). Em decorrência dessa mudança, fala-se da perda da espontaneidade, uma vez que práticas que eram realizadas na rua, e no momento em que eram desejadas, agora acontecem em espaços específicos e com horários bem demarcados (Debortoli et al., 2008). Segundo Neto (2000, p. 2),

a gestão do tempo escolar e o tempo adicional passado em atividades organizadas ou institucionalizadas não permitem às crianças o uso do tempo considerado verdadeiramente livre (espontâneo),

Psicol. Argum. 2014 jul./set., 32(78), 67-78 
consequência provável das transformações urbanas e da construção de imaginários de segurança que os pais tem na educação dos filhos.

Dessa maneira, mais uma vez faz-se necessário lembrar a importância do equilíbrio entre a vivência do tempo livre não estruturado e das atividades organizadas por diferentes instituições para que as crianças experienciem seu desenvolvimento de forma saudável em seus aspectos biológicos, psicológicos e sociais. Contudo, é preciso deixar claro que não se condena as tecnologias, pois possibilitam expandir horizontes através da facilidade de acesso à informação e da comunicação com uma diversidade maior de pessoas. Reconhece-se que a convivência com a mídia faz parte do cotidiano das crianças estudadas. 0 que se propõe é uma observação cuidadosa de como estes instrumentos tem sido utilizados e das influências que podem exercer sobre o desenvolvimento de crianças e adolescentes. Segundo Njaine e Minayo (2004), tais instrumentos não podem ser vistos somente como veículos de comunicação, uma vez que produzem sentidos e constroem valores. É preciso pensar em uma educação crítica e consciente para que seu uso alcance objetivos favoráveis ao desenvolvimento humano.

\section{Referências}

Arruda, F., \& Müller, V. (2010). Brincadeiras e espaços urbanos: um estudo da prática lúdica de crianças de diferentes classes sociais da cidade de Maringá - PR. Licere, 13(4), 1-29.

Bardin, L. (2011). Análise de conteúdo (ed. rev. ampl.). Lisboa: Edições 70.

Bergmann, M., Bergmann, G., Halpern, R., Rech, R., Constanzi, C., \& Alli, L. (2011). Colesterol total e fatores associados: estudo de base escolar no sul do Brasil. Arquivos Brasileiros de Cardiologia, 97(1), 17-25.

Bondía, J. L. (2002). Notas sobre a experiência e o saber da experiência. Revista Brasileira de Educação, 19, 20-28.
Debortoli, J. A. O. (2002). As crianças e as brincadeiras. In A. Carvalho, F. Salles, \& M. Guimarães (Orgs.), Desenvolvimento e aprendizagem (pp. 77-88). Belo Horizonte: UFMG.

Debortoli, J. A. O., Martins, M. F. A., Martins, S. M. M., Senra, E. B., Pimenta, J. G. A., \& Barbosa, R. S. (2008). As experiências de infância na metrópole. In J. A. 0. Debortoli, M. de F. A. Martins, \& S. Martins (Orgs.), Infâncias na metrópole (pp. 19-46). Belo Horizonte: UFMG.

Kishimoto, T. M. (2002). 0 brincar e a qualidade em uma instituição infantil. Licere, 5(1), 23-32.

Meira, A. M. (2003). Benjamin, os brinquedos e a infância contemporânea. Psicologia e Sociedade, 15(2), 74-87.

Molina, M., Faria, C., Montero, M., Cade, N., \& Mill, J. (2010). Fatores de risco cardiovascular em crianças de 7 a 10 anos de área urbana, Vitória, Espírito Santo, Brasil. Cadernos de Saúde Pública, 26(5), 909-917.

Müller, V. R., Rodrigues, J., Ribeiro, L., \& Pelegrini, P. (2007). 0 brincar das crianças: aproximações às culturas infantis. Revista Digital, 11(104). Recuperado em 2013, de http://www.efdeportes.com/efd104/o-brincar-das-criancas-aproximacoes-as-culturas-infantis.htmNeto, C. (2000). o jogo e tempo livre nas rotinas de vida quotidiana de crianças e jovens. In Câmara Municipal de Lisboa - Departamento de Acção Social (Orgs.), Seminário de Tempos Livres: A Criança, o Espaço, a Ideia. Recuperado 2013, de http://www.fmh.utl.pt/Cmotricidade/dm/textoscn/ ojogoetempolivre.pdfNjaine, K., \& Minayo, M. C. de S. (2004). A violência na mídia como tema da área da saúde pública: revisão da literatura. Ciência \& Saúde Coletiva, 9(1), 201-211.

Nunes, A. L. R., \& Becker, L. S. (2000). Corpo, movimento e ludicidade: uma contribuição ao processo de alfabetização. Revista Educação, 25(2), 21-30.

Oliveira, C. M. A. S. (2004). A formação da criança nas cidades. Pediatria, 26(3), 172-178.

Silva Junior, V. P., Tolocka, R., E., \& Marcellino, N. C. (2006). Lazer infantil: direitos legais, transformações sociais e implicações ao crescimento e habilidades motoras básicas. Licere, 9(1), 81-96. 